Tohoku J. exp. Med., 1965, 85, 143-154

\title{
A Study on Oxygen Consumption in the Limbic System, Especially in the Hippocampus
}

\author{
By \\ Yasuhiko Higuchi \\ From the Department of Obstetrics and Gynecology, Tohoku University \\ School of Medicine, Sendai; Director: Prof. $K . K u s h$ i m a \\ (Received for publication, November 6, 1964)
}

\begin{abstract}
The oxygen consumption rate $\left(\mathrm{QO}_{2}\right)$ of the limbic system, especially the hippocampus, of adult rats was measured under various conditions which have been applied to treatment of psychosomatic disease. The $\mathrm{QO}_{2}$ of the brain was lower in female than in male rats. The $\mathrm{Qo}_{2}$ was found to be the highest in the diencephalon, next in the neocortex and the lowest in the limbic system. The hippocampus $\mathrm{Qo}_{2}$ was affected by various conditions, whereas that of the olfactory gyrus was not. The hippocampus $\mathrm{QO}_{2}$ was raised during estrus, recovery from fasting, after glucose injection in the insulin-treated group and by administration of estrogen; while it was lowered during diestrus and by treatment with progesterone, testosterone and chlorpromazine. With noradrenaline and zine gluconate the hippocampus $\mathrm{Qo}_{2}$ tended to decrease slightly. However, meprobamate, reserpin. $\gamma$-oxybutylic acid, monoamine oxidase inhibitor, change in the blood sugar level and electrical stimulation of the olfactory nerve have no effect. In experimental neurosis the 90 minutes value of the hippocampus $\mathrm{QO}_{2}$ tended to be lowered.
\end{abstract}

The reviews of the past researches on the limbie system (LS) show that it is the center of modulatory function of somatic movements, autonomic nervous functions, integration of sensations, urges for food and sex, and emotional manifestations, etc. The emotional disturbance causing psychosomatic disease (PSD) is, in other words, a miscarriage or loss of one's own action. If we admit that all actions are trained or conditioned and that the part played by LS in conditioning is affirmed theoretically, experimentally and clinically, we should become aware of a close correlation between PSD and LS. Owing to the uncertainties about the pathogenesis of PSD, the modes of therapy for it are much diversified. At our clinic, we have obtained a high rate of success in treating such cases by hunger therapy under administration of chlorpromazine concurrently with psychiatric management. On the base of such data, the author undertook the following experiments, in which the hippocampus, the part regarded as the most important

埇口安应 
in the LS, was studied with the aim of getting some clue for elucidating the biological background of genesis of PSD.

\section{MATERIALS AND METHODS}

Materials: Adult Wistar-strain rats, both male and female, weighing about $150 \mathrm{~g}$ and fed in isolation, were killed by decapitation without flurry or delay, then the hippocampus, the gyrus olfactorius, the parietal neocortex and the diencephalon were immediately extracted in the manner given in the handbook, ${ }^{\mathbf{l}}$ put into ice-cooled $0.9 \% \mathrm{KCl}$ solution, and cut into slices about $0.3 \mathrm{~mm}$ thick, for the following process.

Methods: For measurement of the $\mathrm{Qo}_{2}$, the Warburg's manometer was used. The slices were kept floating on $1.5 \mathrm{ml}$ of the Krebs-Ringer phosphate solution containing glucose in $200 \mathrm{mg} / \mathrm{dl}$, of $\mathrm{pH} 7.2$, in the main chamber, and the side chamber was filled with $0.2 \mathrm{ml}$ of a $20 \% \mathrm{KOH}$ solution to absorb $\mathrm{CO}_{2}$, and the gas spaces were filled with oxygen at uniform pressure using a series of $\mathrm{T}$ tubes. The whole outfit was kept shaking (120 shakes per min) in a thermostat at $37.5^{\circ} \mathrm{C}$ for 15 minutes until equilibrium in temperature and pressure was attained. Measurement of $\mathrm{QO}_{2}$ was carried out for one hour. The time between decapitation and beginning of the measurement was about 45 minutes. In the foregoing, the $\mathrm{Qo}_{2}$ is represented in the term of $\mu \mathrm{l} / \mathrm{dry}$ weight $\mathrm{mg} \mathrm{hr}$.

\section{RESULTS}

\section{A. $Q o_{2}$ of $L S$ in normal}

The $\mathrm{Qo}_{2}$ of the hippocampus (Hippo $\mathrm{Qo}_{2}$ ) and the olfactory gyrus of male rats under normal environment and female rats with regular sexual cycle were shown in Fig. 1.

As can be seen in this figure, the $\mathrm{Qo}_{2}$ was higher in male than in femal rats, and no difference in $\mathrm{Qo}_{2}$ between the hippocampus and the olfactory gyrus could be observed in male as well as female rats. In female rats the value of the hippocampus tended to be higher during estrus than during diestrus (estrus here comprising Long Evans' stages II and III, and diestrus their stages IV and V). The relationships between the Hippo $\mathrm{QO}_{2}$ and those of other parts of the brain are illustrated in Fig. 2. In the neocortex the value was nearly equal to or somewhat higher than that in the hippocampus, while that of the diencephalon was definitely higher than that of the hippocampus. In addition, in the diencephalon the value was higher during diestrus than during estrus. This makes a striking contrast to what we have seen in the hippocampus and in the neocortex.

B. Effects of drugs

a) Steroid hormones: Rats during estrus were decapitated 6 hours after hypodermic injection of estradiol $(200 \gamma)$, progesterone $(100 \gamma)$ or testosterone $(1,000 \gamma)$. Rats treated with estradiol showed a rise of the Hippo $\mathrm{Qo}_{2}$, while those 
Oxygen Consumption in Limbic System
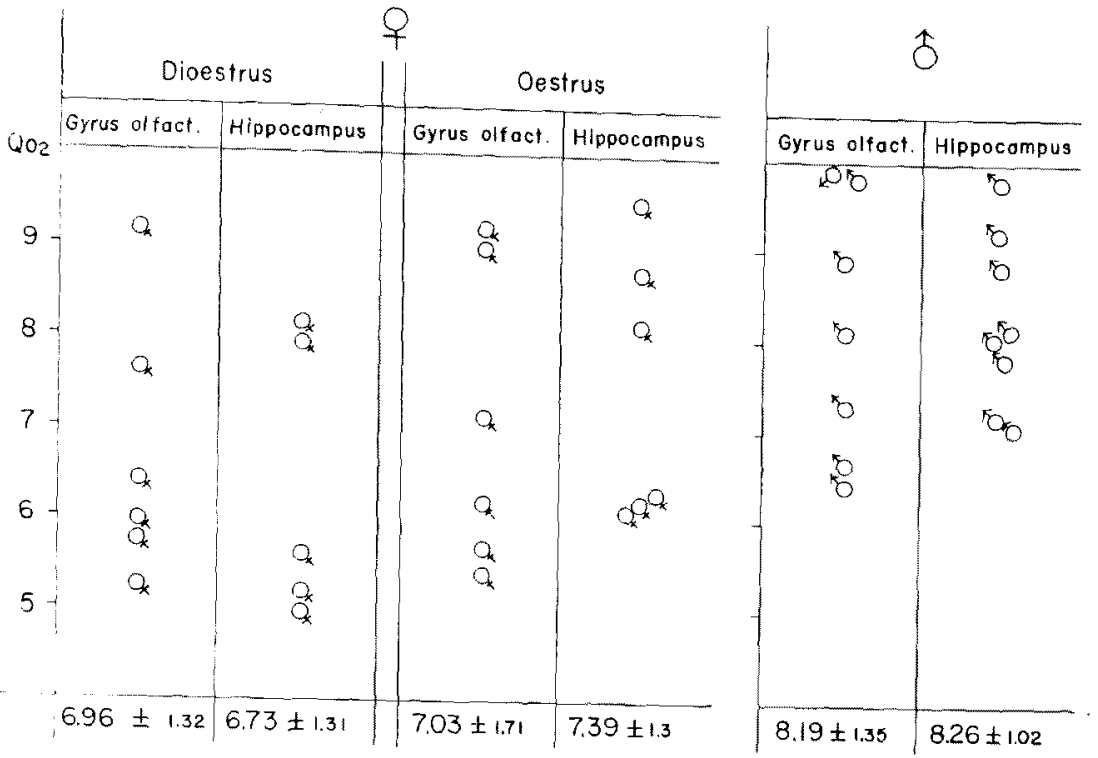

Fig. 1. Qo of $\mathrm{LSS}_{2}$ in normal rats.

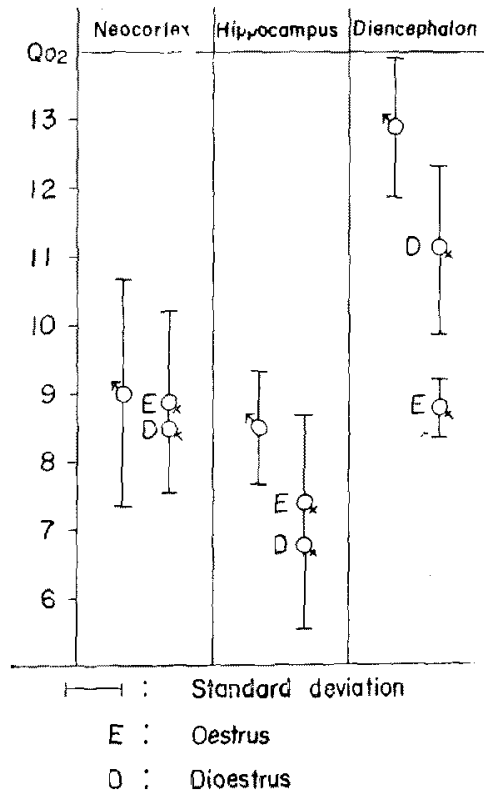

Fig. 2. Hippo $\mathrm{Qo}_{2}$ in comparison with those of other parts of brain. 

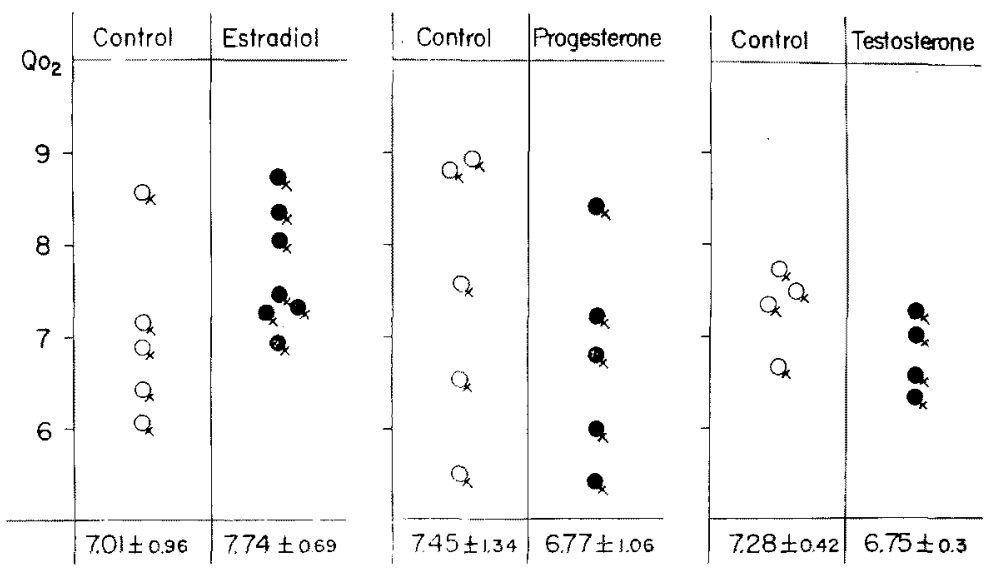

Fig. 3. Effect of steroid sexual hormones on Hippo $\mathrm{Qo}_{2}$.

treated with progesterone or testosterone showed a fall of it (Fig. 3).

b) Tranquilizers: Male rats administered hypodermic injection of $1 \mathrm{mg} /$ $\mathrm{kg}$ of chlorpromazine (Chp) by Gangloff's method ${ }^{2}$ or 2 hours after hypodermic injection of $500 \mathrm{mg} / \mathrm{kg}$ of meprobamate $(\mathrm{Mp})$ by Wikler's method ${ }^{3}$ or of $5 \mathrm{mg} / \mathrm{kg}$ of reserpin ( $\mathrm{Rp}$ ) according to Brodie ${ }^{3}$ showed drowsiness and were quite indifferent before decapitation, but the Hippo $\mathrm{Qo}_{2}$ was found significantly lowered only by Chp but not changed much by any other drugs tested (Fig. 4).

c) GABA ( $\gamma$-aminobutyric acid) and centro-neurotopic drugs: The male rats killed 4 hours after hypodermic injection of $250 \mathrm{mg} / \mathrm{kg}$ of GABA showed little change from the control in general conditions and in the Hippo $\mathrm{Qo}_{2}$, either (Fig. 5).
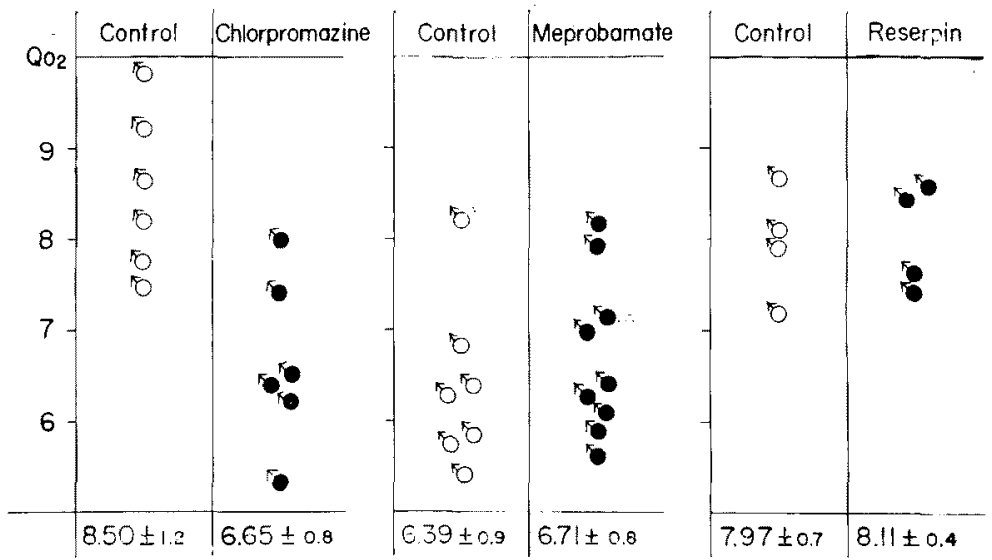

Fig. 4. Effect of tranquilizers on Hippo $\mathrm{Qo}_{2}$. 


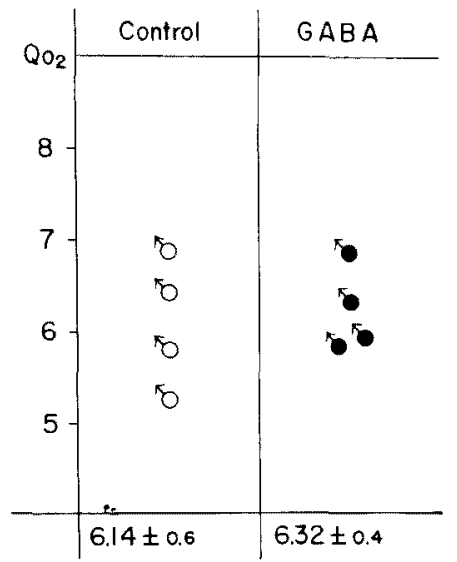

Fig. 5. Effect of GABA on Hippo $\mathrm{QO}_{2}$.

The Hippo $\mathrm{Qo}_{2}$ and the general conditions of the male rats given $7.5 \mathrm{mg} / \mathrm{kg}$ per day of powdered Catron ( $\beta$-phenylisopropyl hydrazin-HCl), a monoamine oxydase (MAO) antagonizer, suspended in water for 3 consecutive days and decaptiated 5 hours after the last treatment were found unchanged (Fig. 6A). Similar results were obtained with a male rat given $160 \gamma / \mathrm{kg}$ of noradrenaline subcutaneously (according to Sobue ${ }^{4}$ ), and killed 20 hours thereafter (Fig. 6B). Next, 2 units/kg of insulin were subcutaneously injected in two groups of male rats, according to Bodansky, ${ }^{5}$ of which the animals of one group were decaptiated 90 minites afterwards and those of the other group were given $2 \mathrm{~g}$ of glucose intraperitoneously and were killed 30-40 minutes thereafter. The former animals
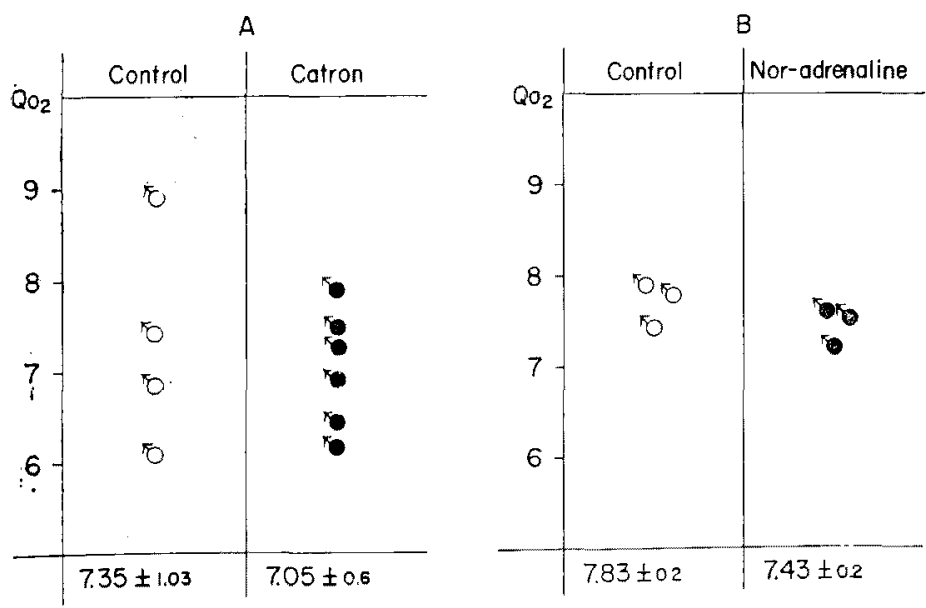

Fig. 6. Hippo $\mathrm{QO}_{2}$ in cases where catecholamine content in brain was changed. 

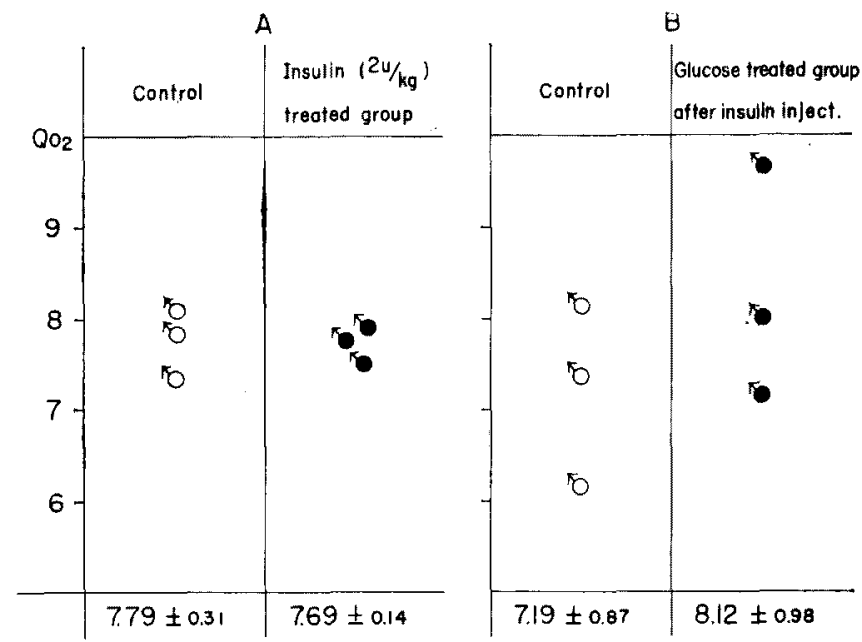

Fig. 7. Hippo $\mathrm{QO}_{2}$ in cases where blood sugar level was changed.

became drowsy and dull, but the latter showed shining eyes and responded actively to external stimuli. The latter alone showed significant rise of the Hippo $\mathrm{Qo}_{2}$ (Fig. 7). Male and estrus female rats were hypodermically injected with $12.5 \mathrm{mg} / \mathrm{kg}$ each of $2.5 \%$ solution of zinc gluconate, $\left(\mathrm{C}_{6} \mathrm{H}_{11} \mathrm{O}_{7}\right) \mathrm{Zn} . \mathrm{H}_{2} \mathrm{O}$, and the $\mathrm{Qo}_{2}$ was measured 2 and 6 hours thereafter. Another male rats was chronically injected with $12.5 \mathrm{mg} / \mathrm{kg}$ of the same daily for 4 consecutive days and the Hippo $\mathrm{Qo}_{2}$ was measured 2 hours after the last injection. All these animals looked dull and sick, but the Hippo $\mathrm{Qo}_{2}$ was found to be lowered only slightly (Fig. 8).

\section{Effect of specific stimulation}

a) Stimulation of the olfactory nerves

1) Electrical stimulation: Female rats in estrus were fixed on an animal board, and stimulating electrodes were inserted deeply in their nasal cavities under light ether anesthesia. After the animal had recovered from ether anesthesia the experiments started after the Cragg's method ${ }^{6}$ in principle, consisting of 5 second stimulation with a current of 1 volt, 100 cycles, and of 10 second stimulation with a current of 1 volt, 10 cycle thereafter. The animals were decapitated 1 minutes after stimulation. Neither seizure nor other behavior disturbance could be observed and the animals remained calm during the stimulation, and no change in Hippo $\mathrm{Qo}_{2}$ was observed after stimulation (Fig. 9B).

2) Stimulation by means of chronic intranasal introduction of $\mathrm{AgNO}_{3}$ solution: In accordance with the method applied by Rosen ${ }^{7}$ in his experiment on pseudocyesis, $0.1-0.2 \mathrm{ml}$ of $10 \%, 20 \%$ and $50 \% \mathrm{AgNO}_{3}$ solutions was given 
A

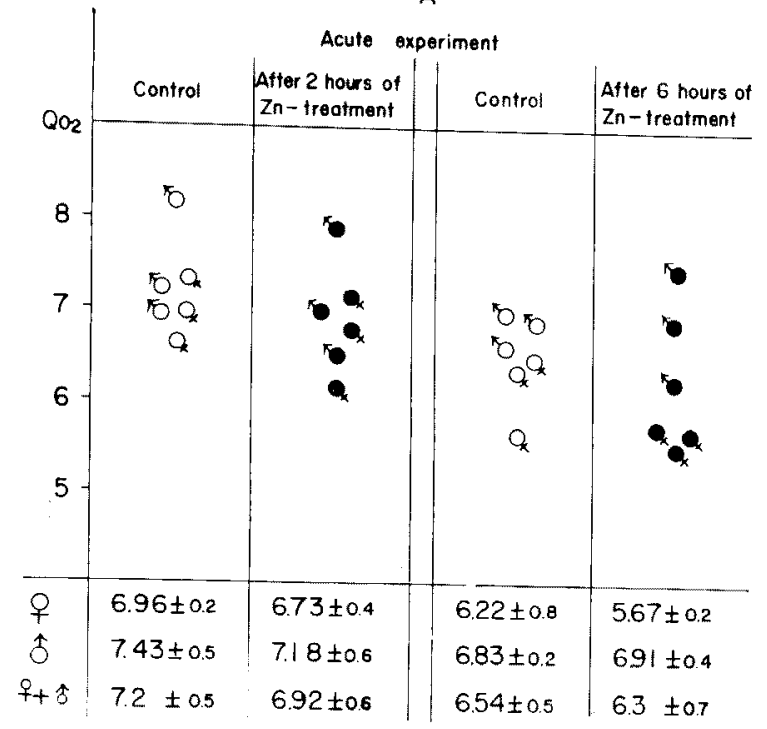

B

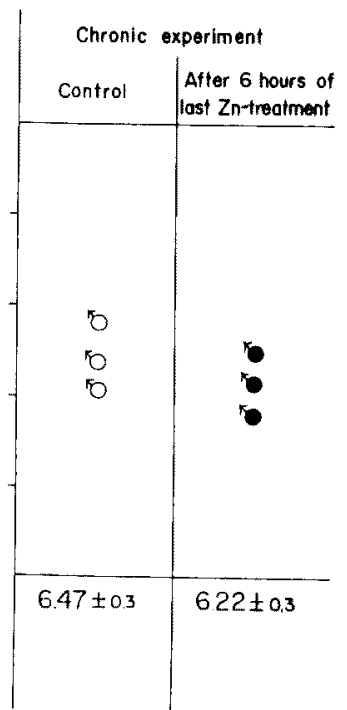

Fig. 8. Effect of zinc gluconate on Hippo $\mathrm{QO}_{2}$.
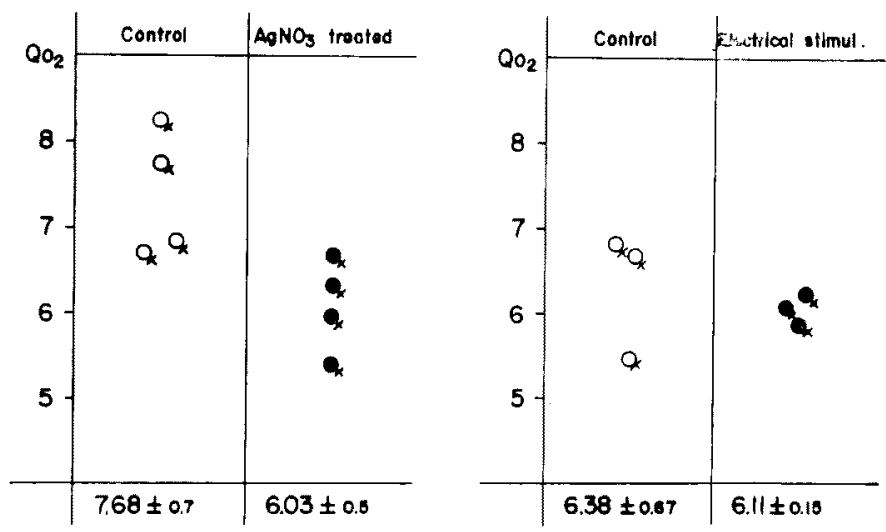

Fig. 9. Effect stimulation of olfactory nerve on Hippo $\mathrm{Qo}_{2}$.

(A) chronic intranasal application of $\mathrm{AgNO}_{3}$.

(B) electrical stimulation of deep nasal cavity.

intranasally for 2 days each in succession under light ether anesthesia. In control animals, the administration was made to the oral cavity, and the animals were decapitated 5 hours after the last administration. In 4 of the 5 tested animals, diestrus set in from the 4th day onward (one of them died during the experiment), but in the control animals the estral cycle was not disturbed. The Hippo $\mathrm{Qo}_{2}$ in the tested animals showed significant regression (Fig. 9). 
b) Experimental neurosis: This anomaly is induced by persistent anxiety, sensory stimulation, forced movement, etc. In this study, the method of forced swimming was adapted to induce neurosis with the principal symptom of body rotation. The results of preliminary experiments showed that the disease culminated around the 4th day of experiment and thereafter alleviated with rapid lengthening of the time of swimming. It was also ascertained that the neurosis is more surely induced in the state of underfeeding. The measurement of $\mathrm{Qo}_{2}$, therefore, was undertaken after killing the animals on the 4th day of experiment, during rottoary motion. As shown in Fig. 10, the 60-minute value of the Hippo $\mathrm{Qo}_{2}$ showed no change from the control, but the 90-minute value
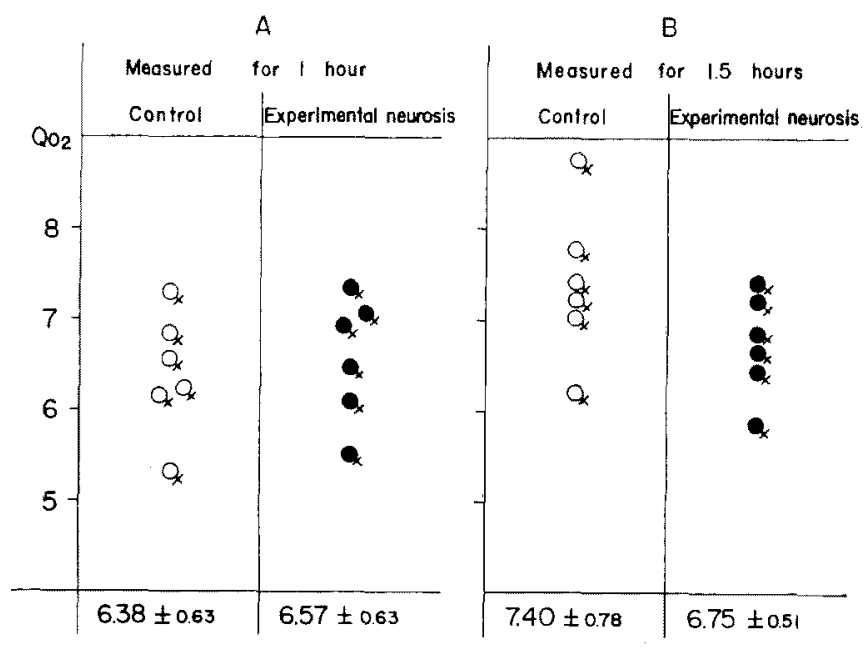

Fig. 10. Hippo $\mathrm{QO}_{2}$ in experimental neurosis.
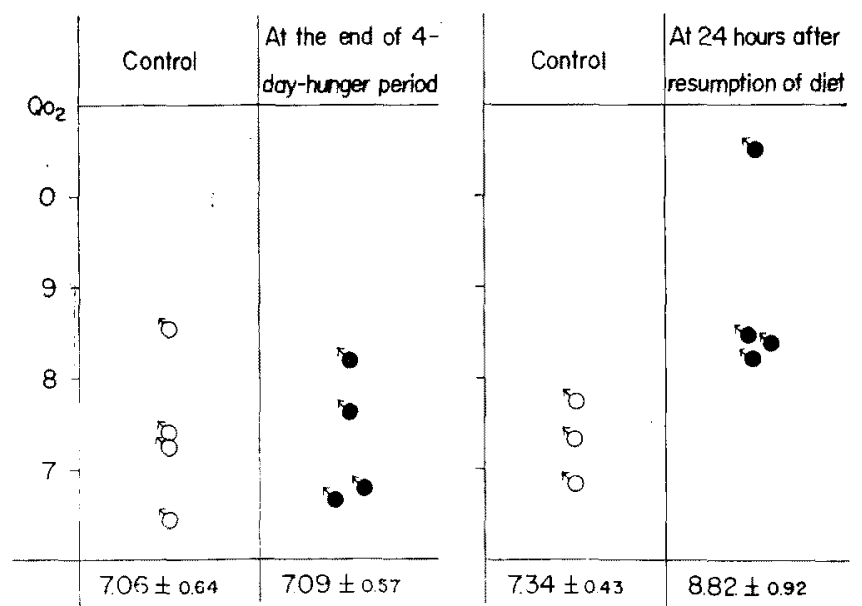

Fig. 11. Hippo $\mathrm{QO}_{2}$ in cases where blood sugar level was changed (cf. Fig. 7). 
tended to lower. Of disorder of the estural cycle, experimenting with 6 animals for 10 days, results obtained were 2 cases each of shortening of diestrus, prolongation of preestrus and normal progress.

c) Fasting: The animals were subjected to complete fasting, water alone being administered and killed in 4 days. The loss in their body weight averaged about $15 \%$, the estrual cycle in them lost regularity, but the Hippo $\mathrm{QO}_{2}$ remained normal. In the case, however, when vegetables and a very moderate amount of cereals was given after 4-day fasting, the Hippo $\mathrm{Qo}_{2} 24$ hours thereafter showed a significantly higher value than the control (Fig. 11).

\section{DISCUSSION}

The LS with the reticular activating system as axis is modulated by the neocortex, is activated by the hypothalamus and is in particularly close relation with the posterior part of the latter. It is sometimes regarded as the modulator of the hypothalamus. Acordingly, a physiological or pathological alteration occurring in the neocortex or the hypothalamus may be expected to affect the function of LS in some way. ${ }^{8}$ It has been found that the electrical activity of the hippocampus is weakened when the diencephalon is stimulated. In my study too, the Hippo $\mathrm{Qo}_{2}$ in each stadium of estrual cycle was found to change antipodally to the diencephalic $\mathrm{Qo}_{2}$. The changes of Hippo $\mathrm{Qo}_{2}$, however, were found to parallel that of the diencephalic $\mathrm{Qo}_{2}$ after injection of the steroid hormones, estrogen and testosterone, both the values rising after the former and falling after the latter. Gordan ${ }^{9}$ observed a similar lowering of encephalic $\mathrm{Qo}_{2}$ after steroid hormone injection, and we cannot neglect here the narcotic effect of it.

In many reports on the inhibitory action of Chp on the central nervous functions, the drug is said to have a tranquilizing effect but no effect on the encephalic $\mathrm{QO}_{2}$, but these reports refer to the parts of the brain outside the hippocampus. Mp was found to inhibit the activity of the TCA cycle and oxydative phosphorylation but in a lower degree than $\mathrm{Chp}$ and in unverified regions, but lately Tokizane ${ }^{11}$ proved that this drug affects the neocortex more than the LS by electroencephalographic studies. $\mathrm{Rp}$ also acts as an uncoupling agent in oxydative phosphorylation, and the brain shows strong sensitivity to it. These tranquilziers always showed obvious tranquilizing effect, but the Hippo $\mathrm{Qo}_{2}$ was lowered after Chp only.

Catron severely impairs the action of MAO and consequently heightens the serotonin and noradrenaline (Norad) contents in the brain, so that it is in use as a pyscho-analeptic. Adrenaline and Norad act in stimulating the reticularactivating system, especially the latter causes increase of secretion resulting from anxiety or persistent mental tension. ${ }^{10}$ It has been proved that Norad is most 
abundant in the hypothalamus and Sobue observed that this agent raises the diencephalic $\mathrm{Qo}_{2}$. According to my studies, however, neither of them showed any effect on the Hippo $\mathrm{Qo}_{2}$. Griesemer, et al. ${ }^{23}$ deny any effect in anti-MAO agents of heightening the efficiency of adrenaline.

The metabolic process in the hippocampus and the amygdaloid nucleus shows a specificity differentiating it from that in any other part of the brain. In particular, zinc is present in these organs alone, but in the hippocampus, its distribution lacks uniformity and suggests a high complexity of its metabolism and consequently a complexity of the function of it. In my experiment of administering zine gluconate, the Hippo $\mathrm{QO}_{2}$ showed a tendency to fall off 2 hours after acute as well as chronic administration of it. Weil-Malherbe ${ }^{12}$ contends that though GABA frankly promotes aerobic generation of lactic acid, it has little or no effect on the brain $\mathrm{Qo}_{2}$ or the phosphoric acid metabolism. In my study, no change was observable.

Why is hunger therapy efficacious in treating PSD? We cannot as yet definitively answer this question. Sensory stimuli related to the fundamental life activities are said to have particularly strong effect in activating the LS, and if we admit that the causative factor of PSD emanates from LS, we may say, as Pavlov would have said, that the strong LS-activating stimulus due to hunger is effective in extinction and correcting the existing faulty pattern of nervous activity. An increase of serotonin in the brain is said to inhibit the impulse transmission at the synapses, and it is known that hunger causes a marked reduction and breaking fast is followed by a rapid increase of serotonin in serum. Eysenck $^{13}$ has found that thirst and hunger affect the formulation and the extinction of conditioned reflex, and Olds and Milner ${ }^{14}$ report that the frequency of reward reactions as tested by Skinner-box method was raised by fasting, in a highest rate under stimulation of LS. It is evident that hunger causes low blood sugar as after insulin injection, and Tokizane ${ }^{11}$ observed seizure discharge arising from the hippocampus in hypoglycemic state following insulin injection. In my study, the Hippo $\mathrm{Qo}_{2}$ was not affected by fasting (the diencephalic $\mathrm{Qo}_{2}$ was lowered), but 24 hours after breaking the fast it rose significantly higher than the control. After insulin, Hippo $\mathrm{QO}_{2}$ was not affected, but it rose significantly higher after insulin and then glucose than after glucose alone.

Miura ${ }^{15}$ has gained successful results in a significant rate by administering electric stimuli to the olfactory nerves of patients with several psychoneuropathies. It is known anatomically and experimentally that a stimulus to the olfactory nerve, relayed by the synapses, indirectly affects the hippocampus. That highcycled preliminary stimuli facilitate both the excitative and the depressant actions of hippocampus has been aflirmed by Cragg. In my followup study of his experiment, no change was found in Hippo $\mathrm{Qo}_{2}$, but when the olfactory nerves were stimulated by continued application of $\mathrm{AgNO}_{3}$ solution according to Rosen's 
method, the Hippo $\mathrm{QO}_{2}$ fell significantly and the diestrus was prolonged. In his paper entitled the "Naso-Gential Relationship", Shelesnyak"17 remarks that stimulation of the olfactory nerves prolongs the estrus, but their narcosis prolongs the diestrus and causes formation of corpus luteum and deciduomata, and such psedocyetic reactions. Dey et al. ${ }^{16}$ observed persistent extinction following destruction of the anterior hypothalamus and stoppage of the estrual cycle following destruction of the posterior hypothalamus. Sawyer ${ }^{18}$ emphazes the significance of the reticular formetion. the rhinencephalon in the process of stimulating gonadotropin secretion. Faure ${ }^{19}$ observed that the excitation of the amygdalohippocampal system is intensified by gonadotropin.

The experimental neurosis induced by forced swimming, like audiogenic neurosis, is characterized by peculiar body rotation and cramps. Asahina ${ }^{20,21}$ reported loss in weight was particularly notable in the medulla oblongata and the cerebellum, and histological changes particularly in the neocortex and the diencephalon. In my study, the Hippo $\mathrm{Qo}_{2}$ was normal in 60 minutes, but tended to decrease in 90 minutes. This may be explained as due to fatigue. A derangement occurred in the estrual cycle in the female cases; similar observation has been reported by Asahina, too.

As described and discussed above, the author studied the Hippo Qo under various conditions chosen from those applied mainly in treatment of PSD. No report on work concerning Hippo $\mathrm{QO}_{2}$ being available, it was inevitable that electrophysiological, histochemical and anatomical informations on the hippocampus should come to the fore in my study. Therefore, the problems of optimum time of decapitation and of appropriate evaluation and discussion of $\mathrm{QO}_{2}$ values are still left for future study, together with the problem of blood brain barrier. Glucose is regarded to offer the sourse of energy metabolism in the brain, but the brain $\mathrm{Qo}_{2}$ does not necessarily run parallel with the rate of sugar consumption, and the Pasteur effect, namely the excitation of cellular function even under inhibited glycolysis, so long as aerobic conditions prevails, is a wellknown fact. This effect has been found particularly obvious after wake-amine administration and in schizophrenia, and it follows that even in the case of functional changes in the brain (e.g., electropotential changes and initial changes under anesthesia), the brain $\mathrm{QO}_{2}$ may be free of significant rise or fall. But the change of brain metabolism reflected in electroencephalograms to a certain extent, and since the sensitivity to the presence of carbon dioxide and oxygen in brain is locally unequal and is known to be stronger in the hippocampns than in the cerebral cortex, ${ }^{22}$ the significant change in $\mathrm{Hippo}_{\mathrm{QO}}$ may help us in estimating the level of activity of the hippocampus. For example, the results of my study concerning estrual cycle, progesterone and chlorpromazine administration or pseudocyesis induced by the stimulation of olfactory nerves seem to suggest that the Hippo $Q o_{2}$ changes antipodally to the diencephalic $Q O_{2}$. 
It may also be pointed out the interesting fact that the Hippo $\mathrm{Qo}_{2}$ changes significantly at the resumptive time of diet in hunger therapy so useful in treament of PSD, after glucose injection in the cases pretreated with insulin, and after chlorpromazine.

\section{Acknowledgment}

The author is greatly indebted to Professor K. Kushima for his advice on the conduct of this study.

\section{References}

1) Winkler, C. \& Potter, C. An Anatomical Guide to Experimental Researches on the Rabbit's Brain, Amsterdam, 1911.

2) Gangloff, H. \& Monnior, M. Helv. physiol. Acta, 1957, 15, 83.

3) Wikler, A. The relation of Psychiatry to Pharmacology, U.S.A, 1957.

4) Sobue, I. Saishin Igaku (Jap.), 1953, 12, 2572.

5) Bodansky, A. Proc. Soc. exp. Biol., 1922/3, 20, 538.

6) Cragg, B.G. Nature, 1959, 184, 1697.

7) Rosen, S. \& Shelesnyak, M.C. Proc. Soc. exp. Biol., 1937, 36, 832.

8) Magoun, H.W. The walking brain, Charles C. Thomas, Springfield, Illinois, 1958.

9) Gordan. G.S. \& Elliott, H.W., Cited fom: Hoagland, H. Hormones, Brainfunction and Behavior, Academic Press Inc. Pub., New York, 1957.

10) von Euler, U.S. Noradrenaline, Charles C. Thomas, Springfield, Illinois, 1956.

11) Tokizane, T. Igaku no Ayumi (Jap.), 1959, 31, 259.

12) Weil-Malherbe, H. Physiol. Rev., 1950, 30, 549.

13) Eysenck, H.J. The Dynamics of Anxiety and Hysteria, Routledge \& Kegan Paul, London, 1957.

14) Olds, J. \& Milner, P., Cited in 13.

15) Miura, T. Jap. med. J., 1959, No. 1822, 7,

16) Dey, F.L., Fisher, C.M. \& Ranson, S.W. Amer. J. Physiol., 1940, 129, 39.

17) Shelesnyak, M.C. \& Rosen, S. Endocrinol., 1938, 23, 58.

18) Sawyer, C.H. Physiological Triggers, Amer. Physiol. Soc., Washington, D.C., 1957.

19) Faure, T. EEG Clin. Neurophysiol., 1957, 9, 361.

20) Asahina. K. Jap. J. Physiol., 1959, 9, 171.

21) Asahina, K. ibid., 1959, 9, 322.

22) Dunlop, C.W. Amer. J. Physiol., 1959, 196, 1079.

23) Griesemer, E.C., Barsky, J., Dragstedt, C.A., wells, J.A. \& Zeller, E.A. Proc. Soc. exp. Biol., 1953, 84, 699. 